\title{
Talasemi Osteoporozunda Zoledronik Asit Kullanımı: Iki Olgu Sunumu ve Literatürün Gözden Geçirilmesi
}

\section{Use of Zoledronic Acid in Thalassemia-Induced Osteoporosis: Two Case Reports and Review of the Literature}

\author{
Pembe Hare YIĞITOĞLU, Rengin GÜZEL, Mehtap EVRAN*, Emel GÜRKAN** \\ Çukurova Üniversitesi Tıp Fakültesi, Fiziksel Tıp ve Rehabilitasyon Anabilim Dalı, Adana, Türkiye \\ *Kahramanmaraş Devlet Hastanesi, Endokrinoloji ve Metabolizma Kliniği, Kahramanmaraş, Türkiye \\ **Çukurova Üniversitesi Tıp Fakültesi, Iç Hastalıkları Anabilim Dalı, Hematoloji Bilim Dalı, Adana, Türkiye
}

\section{Özet}

Talasemi majör hastalarında, erken tanı ve uygulanan tedaviler ile yaşam süresinin uzamasılyla birlikte, osteoporozla ilişkili sorunlar belirgin şekilde artmıştır. Bu hastalarda optimal transfüzyonlarla bile kemik iliği hiperaktif kalmaktadır. Bu nedenle transfüzyonlar, demir şelasyonu ve seks hormonlarıyla optimal tedaviye rağmen jeneralize osteoporoz ve osteopeni talasemide sık görülmektedir. Talasemiye bağlı osteoporozda kemik rezorbsiyonunun artmış olması osteoklast fonksiyonunun potent inhibitörleri olan bifosfonatların kullanımını gündeme getirmiştir. Bu makalede talasemi major ve sekonder osteoporoz tanılarıyla takip edilen iki kızkardeş tartışılmakta ve 6 yıl süre ile uygulanan $4 \mathrm{mg}$ aralıklı zoledronik asit tedavisinin sonuçları sunulmaktadır. Talasemide gelişen osteoporozun etyopatogenezi ve uygulanan tedavi yaklaşımları gözden geçirilmektedir. Türk Fiz Tıp Rehab Derg 2012;58:154-8.

Anahtar Kelimeler: Talasemi, osteoporoz, zoledronik asit

\section{Summary}

The life span of thalassemia major patients has been extended with early diagnosis and treatment modalities. This condition has resulted in an increase in osteoporosis-related problems. Even with optimal transfusions, the bone marrow of these patients remains hyperactive. For this reason, despite blood transfusion, iron chelation, and sex hormone replacement therapy, generalized osteoporosis and osteopenia are still frequent in thalassemia patients. In thalassemia-induced osteoporosis, bone resorption increases. This condition makes biphosphonates, which are potent inhibitors of osteoclast function, the drug of choice. In this article, two sisters with thalassemia major and secondary osteoporosis are discussed and the results of treatment with intermittent zoledronic acid (iv. $4 \mathrm{mg}$ ) for 6 years are presented. We also performed a review of the literature on the etiopathogenesis of thalasemia-induced osteoporosis and the treatment modalities. Turk J Phys Med Rehab 2012;58:154-8.

Key Words: Thalassemia, osteoporosis, zoledronic acid

\section{Giriş}

Kalıtsal multisistemik bir hastalık olan beta-talasemide beta globin zincir sentezi eksik veya azalmıştır. Klinik olarak en ağır betatalasemi tipi talasemi majördür. Nispeten daha hafif, transfüzyon gereksinimi nadiren olan ve daha ileri yaşlarda tanınan talasemi tipi ise talasemi intermedia olarak adlandırılmaktadır. Talasemi minör ise, heterozigot taşıyıcıları tanımlamakta kullanılmaktadır (1,2). 1992 ile
1997 yılları arasında yapılan kapsamlı bir araştırmada İçel ilinde talasemi taşıyıcılığı \%3,1 olarak bulunmuştur (3).

Talasemi majörde beta globin sentezi ciddi bir şekilde azalmış ya da yoktur. Bunun sonucu olarak alfa globin zincir yapımı belirgin olarak artış göstermekte ve inefektif eritropoeze neden olmaktadır. Anemi, hepatosplenomegali ve ekstrameduller hematopoezin neden olduğu iskelet deformiteleri gelişmektedir (1). Kranial kemiklerde ve yüz kemiklerinde genişleme, raşitizm, skolyoz, spinal deformiteler, 
sinir basısı, kırıklar ve ciddi osteoporoz görülebilmektedir (4). Talasemi majörlü hastalarda büyüme geriliği, hipotiroidizm, hipoparatiroidizm, gonadal yetersizlik ve puberte gecikmesi, diabetes mellitus, adrenal yetersizlik, osteoporoz, kardiyak fonksiyon bozukluğu gelişebilmektedir. Kırk dört talasemi majörlü hastanın retrospektif olarak incelendiği bir çalışmada \%61,3'ünde osteoporoz, \%38,6'sında büyüme geriliği, \%25'inde osteopeni, \%13,6'sında hipogonadizm, \%6,8'inde hipotiroidizm, \%4,5'inde hipoparatirodizm, \%2,3'ünde büyüme hormonu eksikliği ve $\% 2,3$ 'ünde tip I diabetes mellitus saptanmıştır (5).

Transfüzyon ve demir şelasyon terapileri ile talasemi majörlü hastaların yaşam süresi dördüncü-beşinci dekadlara kadar uzamıştır. Fakat yaşam süresinin uzaması diğer komorbiditelerin ortaya çıkmasına neden olmuştur $(6,7)$. Kemik iliği ekspansiyonuyla iskelet sistemi hastalıklarından en sık osteoporoz görülmektedir (6).

Talasemiye bağlı osteoporozda artmış osteoklast fonksiyonu sonucu kemik rezorbsiyonunun artmış olması osteoklast fonksiyonunun potent inhibitörleri olan bifosfonatların kullanımını gündeme getirmiştir. Alendronat, klodronat, pamidronat ve zoledronatla yapılmış çalışmalarda zoledronatın en umut vaat eden bifosfonat adayı olduğu saptanmıştır (6).

Bu makalede talasemi majör ve sekonder osteoporoz tanılarıyla takip edilen ve osteoporoza yönelik zoledronat tedavisi uygulanan iki kızkardeş sunulmaktadır.

\section{Olgu 1}

2002 yılında 26 yaşındayken eklem kısıtlıı̆̆ı ve ağı yakınması ile Fiziksel Tıp ve Rehabilitasyon polikliniğine başvuran kadın hasta o dönemden beri izlemimizdedir. Öyküsünden 3 yaşındayken talasemi majör tanısı konulduğu ve 6 yaşından beri aralıklı kan transfüzyonu uygulandığı, 16 yaşındayken splenektomi yapıldığı ve aynı yaşta sol femur şaft kırığı olduğu, 20 yaşında sağ femur boyun kırığı sonrası total kalça protezi uygulandığı, 31 yaşında iken üst gastrointestinal kanama geçirdiği öğrenildi. Solda kruris bölgesinde ve ayak bileğinde de kırık öyküsü mevcuttu.

Hastanın 34 yaşındaki muayenesinde talasemiye özgü yüz görünümü mevcut olup, boy: $141 \mathrm{~cm}$, kilo 39 kg idi. Sağda aksiller destekli koltuk değneği, solda $12 \mathrm{~cm}$ 'lik tabanlık takviyeli ayakkabı kullanıyordu. Kalp oskültasyonunda $2 / 6$ sistolik üfürümü vardı, karaciğer sert kıvamlıydı ve kot altında $5 \mathrm{~cm}$ palpe ediliyordu, splenektomiye ait insizyon skarı mevcuttu. Sol diz fleksiyonu $10^{0}$ idi, spina iliaka anterior süperior-iç malleol arası ölçümde solda sağa göre 13 cm'lik kısalık mevcuttu. Hastada Thomas testi bilateral pozitif olup $15^{\prime}$ er derece fleksiyon kontraktürü mevcuttu. Sağ kalçanın dış rotasyonu $30^{\circ}$ ve fleksiyonu $100^{0}$ idi. Sağ dizde $10^{0}$ fleksiyon kontraktürü vardı ve genu valgum deformitesi mevcuttu. Sol ayak dorsifleksiyonu $10^{0}$ idi.

Hastanın son biyokimyasal tetkikleri Tablo 1'de özetlendi.

Grafilerinde tüm kemik yapılarda diffüz dansite azalması, çok sayıda kortikal ve medüller kistler izleniyordu (Resim 1,2).

Hastaya desferrioksamin tedavisinin haftada 6 gün 1 gr ile haftada 4 gün 2 gr arası dozlarda önerildiği, ancak hastanın tedaviye uyumunun düşük olduğu öğrenildi. 25 yaşındayken ovaryan yetmezlik tanısı konularak hormon replasman tedavisi başlanan hasta ayrıca $50 \mathrm{mg}$ spironolakton-50 mg hidroklorotiazid kombinasyonu, $40 \mathrm{mg}$ furosemid, $5 \mathrm{mg}$ folik asid ve $25 \mathrm{mg}$ çinko tedavisi almaktaydı.

Osteoporoza yönelik olarak 2002 yılında kalsitonin nazal sprey 200 IU önerilen hastanın daha sonra hormon replasman, kalsiyum, aktif vitamin $D$ ve risedronat tedavisine rağmen kırık geçirmeye devam etmesi üzerine zoledronat tedavisine geçilmesine karar verildi. Hastaya 2003-2006 yılları arasında 4 mg IV zoledronat tedavisi 6 ayda bir infüzyon şeklinde uygulandı, 2007 yılında infüzyonlar 3 ay ara ile yapıldı, 2008 yılında 4 ayda bir infüzyon şeklinde tedavisi sürdürüldü ve 2009 yılında 6 ay ara ile iki infüzyon uygulandıktan sonra DXA değerlerinin stabil seyretmesi üzerine tedaviye ara verildi, sadece 1000 mg kalsiyum ve 880 IU vitamin D ile devam etmesi ve yıllık DXA ölçümleri ile izlenmesi planlandı. Zoledronat tedavisine geçildikten sonra yeni kırık geçirmeyen hastanın yıllar içindeki T-skoru ve Z-skoru değişimleri tabloda verildi (Tablo 2).

Tablo 1. Talasemi majör olgularının biyokimyasal parametreleri.

\begin{tabular}{|l|c|c|}
\hline & Olgu1 & Olgu2 \\
\hline Beyaz küre (4-10 uL) & $14,2(\uparrow)$ & $14,9(\uparrow)$ \\
\hline Hemoglobin $(11-18 \mathrm{~g} / \mathrm{dL})$ & $10,3(\downarrow)$ & $9,1(\downarrow)$ \\
\hline Hematokrit $(37-54 \%)$ & $30,0(\downarrow)$ & $25,9(\downarrow)$ \\
\hline Trombositler $(150-500 \mathrm{uL})$ & 376 & $575(\uparrow)$ \\
\hline Eritrosit sedimantasyon hızı (0-25 mm/saat) & 10 & $33(\uparrow)$ \\
\hline C-reaktif protein $(0-8,2 \mathrm{mg} / \mathrm{L})$ & $11,1(\uparrow)$ & $8,6(\uparrow)$ \\
\hline Ferritin $(15-200 \mathrm{ng} / \mathrm{ml})$ & $1966(\uparrow)$ & $4839(\uparrow)$ \\
\hline Kreatinin $(0,6-1 \mathrm{mg} / \mathrm{dL})$ & $0,37(\downarrow)$ & $0,46(\downarrow)$ \\
\hline Alkalen fosfataz $(5-240 \mathrm{U} / \mathrm{L})$ & $339(\uparrow)$ & 184 \\
\hline Albumin $(3,4-4,8 \mathrm{~g} / \mathrm{dL})$ & 4,3 & 4,4 \\
\hline Aspartat aminotransferaz $(<31 \mathrm{U} / \mathrm{L})$ & $31(\uparrow)$ & $32(\uparrow)$ \\
\hline Alanin aminotransferaz $(<31 \mathrm{U} / \mathrm{L})$ & $68(\uparrow)$ & 25 \\
\hline Gama glutamiltransferaz $(7-32 \mathrm{U} / \mathrm{L})$ & $151(\uparrow)$ & 12 \\
\hline Kalsiyum $(8,8-10,2 \mathrm{mg} / \mathrm{dL})$ & 9,0 & 9,2 \\
\hline 25-OH Vit D3 (20-120 ng/mL) & 22,5 & 28 \\
\hline
\end{tabular}

Tablo 2. Talasemi majör olgularının AP lomber omurga ortalama T-skorları ve Z-skorlarında yıllar içindeki değişim.

\begin{tabular}{|l|l|l|l|l|}
\hline & \multicolumn{2}{|c|}{ Olgu 1 } & \multicolumn{2}{c|}{ Olgu 2 } \\
\hline & Z-skoru & T-skoru & Z-skoru & T-skoru \\
\hline $04.2003^{*}$ & $-5,5$ & $-5,6$ & Hesaplanmamış & $-5,2$ \\
\hline $09.2003^{*}$ & $-3,8$ & $-3,9$ & Hesaplanmamış & $-5,3$ \\
\hline $03.2004^{*}$ & $-4,1$ & $-4,2$ & $-4,8$ & $-4,8$ \\
\hline $10.2004^{*}$ & $-4,1$ & $-4,3$ & $-4,5$ & $-4,6$ \\
\hline $04.2005^{*}$ & $-4,3$ & $-4,5$ & $-3,5$ & $-3,6$ \\
\hline $11.2005^{\dagger}$ & $-3,5$ & $-3,5$ & $-3,3$ & $-3,3$ \\
\hline $10.200 \dagger^{\dagger}$ & $-2,5$ & $-2,6$ & $-2,5$ & $-2,5$ \\
\hline $09.2008^{\dagger}$ & $-2,6$ & $-2,6$ & $-2,1$ & $-2,1$ \\
\hline $05.2009^{\dagger}$ & $-2,4$ & $-2,5$ & $-2,5$ & $-2,5$ \\
\hline $02.2010^{\dagger}$ & $-2,6$ & $-2,6$ & $-2,2$ & $-2,2$ \\
\hline
\end{tabular}

Ölçüm yapılan cihaz: *Norland Bone Densitometer, Medical Systems, Inc; †Hologic QDR-4500 scanner 


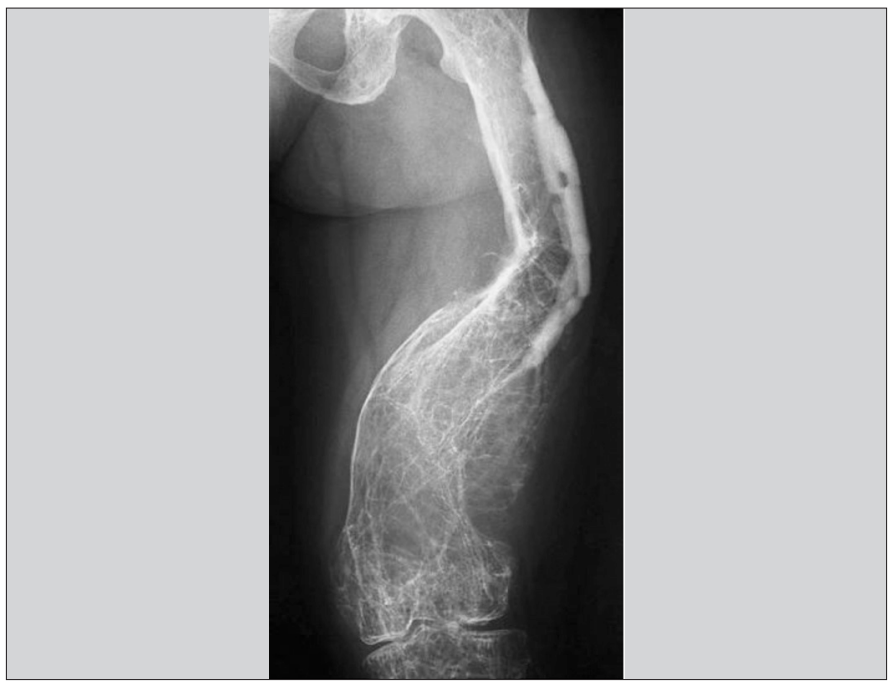

Resim 1. Olgu 1'in ön-arka femur grafisi.

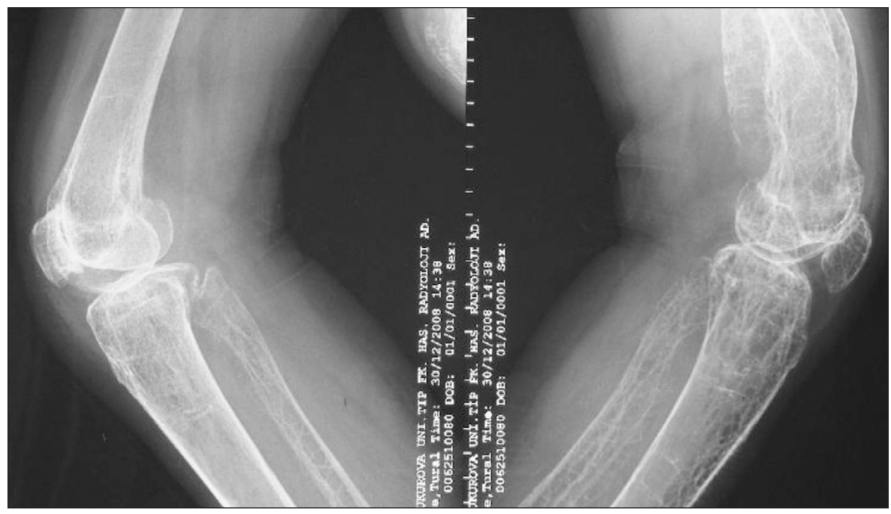

Resim 2. Olgu 1'in lateral diz grafileri.

\section{Olgu 2}

2003 yılında 24 yaşındayken polikliniğimize başvuru yapan diğer kızkardeşe ise talasemi majör tanısının bir yaşındayken konulduğu ve transfüzyon tedavisi başlandığı, 13 yaşındayken splenektomi yapıldığı ve desferrioksamin tedavisine uyumsuz olduğu öğrenildi. Kırık öyküsü olmayan hastanın 31 yaşındaki muayenesinde boy:159 $\mathrm{cm}$, kilo: $44 \mathrm{~kg}$ idi. Sol dizinde $10^{0}$ fleksiyon kontraktürü mevcuttu ve bilateral kalça dış rotasyonları 200 idi.

Bu hastaya hormon replasman tedavisi 23 yaşındayken başlandı, kalsiyum ve vitamin D desteğinin yanı sıra 25 yaşındayken (2004 yılında) 6 ayda bir infüzyon şeklinde $4 \mathrm{mg}$ IV zoledronat tedavisi önerildi. Kırık geçirmeyen hastanın yıllar içindeki T-skoru ve Z-skoru değişimleri tabloda verildi (Tablo 2). DXA değerlerinin stabil seyretmesi üzerine 2009 yılında tedaviye ara verildi, sadece 1000 mg kalsiyum ve 880 IU vitamin D ile devam etmesi ve yıllık DXA ölçümleri ile izlenmesi planlandı.

\section{Tartışma}

Talasemi majörlü hastalarda optimal transfüzyonlarla bile kemik iliği hiperaktif kalmaktadır. Bu nedenle transfüzyonlar, şelasyon ve seks hormonlarıyla optimal tedaviye rağmen jeneralize osteoporoz ve osteopeni sık görülmektedir (1). Talasemiye bağlı osteoporoz, uygun transfüzyon ve demir şelasyon tedavisine rağmen talasemi majörlü hastaların \%30-50'sinde görülmektedir (6,8). Kırık prevalansı talasemi majörlü hastalarda \%16,6, talasemi intermediali hastalarda \%12,2'dir (9). Yaşam süresi uzadıkça osteoporoz, yetişkin talasemi majörlü hastalarda morbidite ve dizabilitenin önemli nedeni olmuştur (7).

Talasemi hastalarında osteoporoz patogenezinde genetik faktörler ve kazanılmış faktörler rol oynamaktadır. Gen polimorfizmi ve kemik kütlesi arasındaki ilişkinin belirlenebilmesi için daha fazla çalışmaya gerek duyulsa da, kollajen tip la1 geninin Sp1 bölgesindeki polimorfizm, talaseminin neden olduğu osteoporozda önemli görünmektedir. Sp1 mutasyonu taşıyan erkek talasemi majörlü hastalarda bu mutasyonu taşımayanlara göre omurga ve kalça osteoporozunun daha ciddi olduğu bulunmuştur (10). Kazanılmış faktörler arasında osteopeni veya osteoporozun temel sebepleri olarak belirlenmiş olan hipotiroidizm, hipoparatiroidizm, diabetes mellitus, hipogonadizm ve kemik döngüsünde önemli rol oynayan insülin benzeri büyüme faktörü düşüklüğü gibi endokrin komplikasyonlar önemlidir. Bunun yanı sıra kan transfüzyonlarına ikincil olarak gelişen demir aşırı yükü osteoid maturasyonunun bozulmasına ve mineralizasyonunun lokal olarak inhibisyonuna neden olmaktadır. Demir aşırı yükünü ortadan kaldırmak için önerilen desferrioksamin şelasyon tedavisi ise, DNA sentezini, osteoblast ve fibroblast proliferasyonunu, osteoblast prekürsör farklılaşmasını ve kollajen formasyonunu inhibe etmekte ve osteoblast apopitozunu arttırmaktadır. Ayrıca kemik iliği ekspansiyonu, vitamin C ve vitamin D eksiklikleri, fizik aktivite azlığı, artmış osteoklast fonksiyonu ve azalmış osteoblast fonksiyonu da talasemi majördeki osteoporoz nedenleri arasında sıralanmaktadır $(1,8,9,11)$.

Genel populasyonda osteoporoz, kadınlarda daha sık görülmesine rağmen, talasemi hastalarında erkeklerde daha sık görülmektedir. Erkekler düşük kemik kütleleriyle daha sık ve daha ciddi etkilenmektedir. Bu çarpıcı sonuç, erkek talasemi hastalarının adölesan dönemlerinde desferrioksamin tedavisine uyumsuz olmalarıyla açıklanmaktadır (12). Bizim olgularımızda da desferrioksamin tedavisine uyumsuzluk şiddetli osteoporozun bir nedenidir. Talasemi hastalarında osteoporoz ve osteopeninin, trabeküler ve kortikal kemikten oluşan femur boynundan daha fazla, trabeküler kemikten oluşan omurgada belirgin olduğu saptanmıştır (4). Bizim olgularımızda da hem lomber hem de kalça kemik mineral yoğunluğu (KMY) ölçümleri yapılmış ve lomber omurga ölçümlerinin, kalça ölçümlerine göre daha düşük olduğu görülmüştür.

Osteoporotik kırıkların dağılımı genel populasyonla aynıdır fakat genç talasemik hastalar yüksek vertebral kırık insidansina sahiptir (1). Bizim birinci olgumuzda da femur boyun kırığını da içermek üzere ekstremitelerde çeşitli kırıklar görülmüştür.

Talasemik hastalarda neoformasyon fazının sabit kaldığı, rezorbsiyon fazının arttığı, dengede olmayan kemik döngüsü vardır. Bu da, negatif kemik dengesine ve dolayısıyla KMY kaybına neden olmaktadır. Bu bilgi, talasemik hastaların osteoporoz tedavisinde bifosfonatlar gibi güçlü anti-rezorptif ilaçların kullanılmasını desteklemektedir (7). Alendronat, pamidronat ve zoledronat gibi bisfosfonatların kemik döngüsü hızını normalleştirdiği ve KMY artışında etkili olduğu saptanmıştır (9). 
Morabito ve ark'nın (13) yaptığı bir çalışmada, iki yı boyunca günlük oral $10 \mathrm{mg}$ alendronat ve IM $100 \mathrm{mg}$ klodronat (10 günde bir infüzyon) karşılaştırılmış, klodronat tedavisi alan grupta KMY'de artma olmazken alendronat alan grupta omurga ve kalça KMY'sinde artma olmuştur.

Pamidronat ile yapılan çalışmalarda ise aylık $15 \mathrm{mg}, 30 \mathrm{mg}$ veya 60 mg pamidronat kullanımı ile KMY'de artış saptanmıştır $(10,14)$. Türkiye'de yapılan bir çalışmada Patıroğlu ve arkadaşları (15) 23 hastaya bir yıl süreyle 3 ayda bir $15 \mathrm{mg}$ pamidronat tedavisi uygulamış, bir yıllık tedaviden sonra sadece kalsiyum ve vitamin D desteği sağlanmıştır. Bir yıl sonunda femur boyun KMY'sinde önemli artış sağlanırken, lomber vertebra KMY'sindeki artış istatistiksel olarak anlamlı bulunmamıştır. Tedaviden iki yıl sonra ise hem femur boynu hem de lomber vertebra KMY'sinde anlamlı artış saptanmıştır (15).

Zoledronat ile yapılan çalışmalarda da farklı dozlar, farklı aralıklarla kullanılmıştır. Voskaridou ve arkadaşlarının (16) çalışmasında 1 yıl süreyle bir gruba 6 ayda bir IV 4 mg zoledronat, diğer gruba 3 ayda bir IV 4 mg zoledronat, bir diğer gruba ise 3 ayda bir plasebo tedavisi verilmiş, 3 ayda bir IV $4 \mathrm{mg}$ zoledronat alan hastaların lomber omurga KMY'lerinin arttığı, plasebo grubunda ise değişmediği bulunmuştur. Takip eden bir yayınlarında zoledronatın kesilmesinden sonra da etkisinin devam ettiğini bildirmişlerdir (17). Perifanis ve arkadaşlarının (18) yaptığı çalışmada 12 ay boyunca her 3 ayda bir $1 \mathrm{mg}$ IV zoledronat tedavisi uygulanmış ve lomber omurga KMY'sinde artış tespit edilmiştir. Gilfillan ve arkadaşları (19) ise 24 ay boyunca 4 ayda bir $4 \mathrm{mg}$ IV zoledronat tedavisi vermişler, plasebo ile kıyaslandığında hem lomber hem de femoral KMY'de artma olduğunu saptamışlardır. Çukurova bölgesinde yapılan, tedavi öncesi 1,25-dihidroksivitamin D düzeyleri normal olan 39 hastanın katıldığı bir yıllık çalışmada, zoledronat (6 ayda bir IV $4 \mathrm{mg}$ ) ve kalsitriol $(0,25 \mathrm{mcg} / \mathrm{gün})$ tedavileri karşılaştırılmış ve zoledronat tedavisi alan grupta lomber, kalsitriol tedavisi alan diğer grupta ise femur boyun KMY değerlerinde anlamlı artış saptanmıştır. Bu çalışmada lomber vertebra ve femur boynu KMY değerleri ile $\mathrm{T}$ skorundaki değişimlerde tedavi grupları arasında fark bulunamamıştır (2).

Bizim olgularımızda da farklı zaman aralıkları ile uygulanan 4 mg iv. zoledronat tedavisi iyi tolere edilmiş olup, herhangi bir yan etkiye rastlanmamıştır. Olguların lomber KMY ölçümlerinde belirgin düzelme saptanmış ve tedaviye başlandıktan sonra yeni kırık oluşmamıştır. Birinci olguda tedavi aralıklarının daha sık olmasının sebebi sık kırık öyküsü olmasıdır ve bu konu ile ilgili yapılan yayınlarda da farklı aralıklarla uygulamalar yapılmıştır (2,16-19).

Osteoporoz hastasının izleminde DXA ölçümlerinin bir yıl ya da daha uzun aralıklarla yapılması, daha sık tekrarın ise hızlı kemik kaybı ile ilişkili özel koşullarda düşünülmesi önerilmektedir (20). Bizim olgularımızı izlemeye başladığımız ilk yıllarda DXA ölçümlerinin sık aralıklarla yapılmasının nedeni birinci olgunun sık kırık öyküsü olması ve o dönemlerde DXA ölçümünün hangi sıklıkla yapılması gerektiğinin tam netlik kazanmamış olmasıydı. DXA ölçümlerinde lomber ölçümlerin yanı sıra kalça bölgesinden de ölçümler yapılmış ancak ölçümler geriye dönük olarak incelendiğinde bazı ölçümlerin sağ, bazılarının soldan yapıldığı ve ölçümlerin hepsinde kalçanın uygun pozisyonlanmasının sağlanamadığı görüldüğünden bu değerler makalede verilmemiştir. Uluslararası Klinik Dansitometre Derneği önerileri takiplerin aynı cihaz kullanılarak, aynı teknisyen tarafından yapılması gerektiği yönündedir (20) ve bizim olgularımızın izleminin sürdüğü 7 yıl içinde bu gerekliliğin yerine getirilemediği açıktır. Literatürde farklı cihazlarla yapılan KMY sonuçlarının karşılaştırılabilmesi için bazı çevirim formülleri $(21,22)$ önerilmiş olsa da bizim olgularımızda tedavi sonucunda meydana gelen $T$ ve $Z$ skor değişiklikleri dikkat çekici boyutta olduğu için tüm kısıtlılıklarına rağmen etkinlik değerlendirmesi amacıyla kullanılmıştır. Bunun yanı sıra yeni kırık oluşmaması da tedavinin etkinliği yönünden iyi bir kanıt oluşturmaktadır. Ancak literatürde talasemi osteoporozunda zoledronat tedavisinin kırık riskini azalttığıyla ilgili bir çalışma sonucu yoktur (9).

Zoledronat tedavisinin eritropoietik aktiviteyi arttırdığı (23) ve bunun da tedavi kesildikten sonra bile $\mathrm{KMY}^{\prime}$ de uzun dönem artmaya neden olduğu gösterilmiştir (17). Tedavi ile kemik rezorbsiyon ve formasyon belirteçlerinin azalması ilacın kemik döngüsünü azaltarak etki gösterdiğini düşündürmektedir (6). Genel olarak zoledronat tedavisinin iyi tolere edildiği ve ağrıyı azalttığı da gösterilmiştir $(6,9)$. Ancak uzun süreli IV bifosfonat tedavilerinin bu hastalardaki yan etki profili bilinmemektedir. Her ne kadar talasemik hastalarda hiç bildirilmemiş olsa da malignite hastalarında kullanılan iv bifosfonatlar çene osteonekrozu ile ilişkilendirilmektedir $(9,24)$. Bunun yanısıra postmenapozal osteoporoz hastalarında $5 \mathrm{mg}$ zoledronat ile yapılan bir çalışmada (25) atrial fibrilasyon riski yüksek olarak saptanmış ancak daha sonraki çalışmalarda böyle bir risk artışı olmadığı kanaatine varılmıştır (26). Talasemi majör hastalarında kardiyak komplikasyonların primer mortalite nedeni olduğu gözönüne alınacak olursa bu bilginin de akılda tutulması ve yeni çalışma sonuçlarının izlenmesi gerekmektedir (27).

Sonuç olarak; talasemi ile ilişkili osteoporoz multifaktöryeldir ve tedavisi zordur. Osteoporoz ilerleyici bir hastalıktır ve dolayısıyla önlenmesi ve erken tanısı çok önemlidir. Talasemi majörlü hastalarda uygun hormon replasmanına gecikmeden başlanması, etkili demir şelasyonu, hemoglobin değerlerinde artışın sağlanması, kalsiyum ve vitamin $D$ desteğinin optimal olması, fizik aktivitenin arttırıması, sigaranın bırakılması hastalıkla mücadeledeki temel yaklaşımlardır. Bu hastalarda osteoporoz tedavisinde bifosfonatların kullanımı ile olumlu sonuçlar alınmıştır (8).

Burada sunulan iki olguda; demir şelasyon tedavisine uyumsuzluk, hormon replasman tedavilerine geç yaşta başlanmış olması ve kırıklarla birlikte immobilizasyon osteoporoz şiddetini arttıran önemli nedenlerdir. Her iki olguda da zoledronat tedavisi iyi tolere edilmiş, ağrıyı azaltmış ve yeni kırıkları engellemiştir. Olguların takiplerinin yıllık DXA ölçümleri ile sürdürülmesi ve değerlerde azalma saptanırsa zoledronat tedavisine tekrar başlanması planlanmaktadır.

Zoledronat tedavisi talasemi majörün oluşturduğu osteoporozda etkin ve güvenilir gözükmektedir. Fakat bifosfonatlar yaygın kullanılmaya başlamadan önce hangisinin, ne kadar süreyle, hangi dozda kullanılacağı gibi pek çok konu netleşmelidir. Randomize çalışmalarla diğer etkili ajanlarla bifosfonatların kombinasyonu değerlendirilmelidir.

\section{Çıkar Çatışması:}

Yazarlar herhangi bir çıkar çatışması bildirmemişlerdir. 


\section{Kaynaklar}

1. Tyler PA, Madani G, Chaudhuri R, Wilson LF, Dick EA. The radiological appearances of thalassaemia. Clin Radiol 2006;61:40-52.

2. Evren M. Beta talasemili hastalarda osteoporoz ve osteoporoz tedavisinde zoledronik asit kullanımı (tıpta uzmanlık tezi). Adana: Çukurova Üniversitesi; 2005.

3. Kılınç $M$, Koçak F, Yüreğir $G$, Aksoy K. Içel ilinde orak hücre anemisi ve ß-talasemi taşıyıcılık sıklığı. Ç.Ü. Tıp Fakültesi Dergisi 1999;24:62-5.

4. Perrotta S, Cappellini MD, Bertoldo F, Servedio V, Iolascon G, D'Agruma $L$, et al. Osteoporosis in beta-thalassaemia major patients: analysis of the genetic background. $\mathrm{Br}$ J Haematol 2000;111:461-6.

5. Baytan B, Sağlam H, Erdöl Ş, Beyazıt AN, Özgür T, Güneş AM, ve ark. Talasemi majörlü vakalarda endokrin komplikasyonların değerlendirilmesi. Güncel Pediatri 2008;6:58-65.

6. Mamtani $\mathrm{M}$, Kulkarni $\mathrm{H}$. Bone recovery after zoledronate therapy in thalassemia-induced osteoporosis: a meta-analysis and systematic review. Osteoporos Int 2010:21:183-7.

7. Perifanis V, Vyzantiadis T, Tziomalos K, Vakalopoulou S, Garipidou V, Athanassiou-Metaxa $\mathrm{M}$, et al. Effect of zoledronic acid on markers of bone turnover and mineral density in osteoporotic patients with betathalassaemia. Ann Hematol 2007;86:23-30.

8. Terpos E, Voskaridou E. Treatment options for thalassemia patients with osteoporosis. Ann N Y Acad Sci 2010;1202:237-43.

9. Gaudio A, Morabito N, Xourafa A, Macrì I, Meo A, Morgante S, et al. Bisphosphonates in the treatment of thalassemia-associated osteoporosis. J Endocrinol Invest 2008;31:181-4.

10. Wonke B, Jensen C, Hanslip JJ, Prescott E, Lalloz M, Layton M, et al. Genetic and acquired predisposing factors and treatment of osteoporosis in thalassaemia major. I Pediatr Endocrinol Metab 1998;11(3 suppl):795-801.

11. Voskaridou E, Terpos E. New insights into the pathophysiology and management of osteoporosis in patients with beta thalassaemia. $\mathrm{Br} J$ Haematol 2004;127:127-39.

12. Jensen CE, Tuck SM, Agnew JE, Koneru S, Morris RW, Yardumian A, et al. High prevalence of low bone mass in thalassaemia major. $\mathrm{Br}$ Haematol 1998;103:911-5.

13. Morabito N, Lasco A, Gaudio A, Crisafulli A, Di Pietro C, Meo A, et al. Biphosphonates in the treatment of thalassemia-induced osteoporosis. Osteoporos Int 2002;13:644-9.

14. Voskaridou E, Terpos E, Spina G, Palermos J, Rahemtulla A, Loutradi A, et al. Pamidronate is an effective treatment for osteoporosis in patients with beta-thalassemia. Br J Haematol 2003;123:730-7.

15. Patıroğlu T, Altuner Torun $Y$, Kula $M$, Karakükçü $M$. Treatment of thalassemia-induced osteoporosis with intermittent pamidronate infusions: two-year follow-up. Turk J Hematol 2008;25:79-82.
16. Voskaridou E, Anagnostopoulos A, Konstantopoulos K, Stoupa E, Spyropoulou E, Kiamouris C, et al. Zoledronic acid for the treatment of osteoporosis in patients with beta-thalassemia: results from a singlecenter, randomized, placebo-controlled trial. Haematologica 2006;91:1193-202.

17. Voskaridou E, Christoulas D, Konstantinidou M, Tsiftsakis E, Alexakos P, Terpos E. Continuous improvement of bone mineral density two years post zoledronic acid discontinuation in patients with thalassemiainduced osteoporosis: long term follow up a randomized, placebocontrolled trial. Haematologica 2008;93:1588-90.

18. Perifanis V, Vyzantiadis T, Vakalopoulou S, Tziomalos K, Garypidou V, Athanassiou-Metaxa $\mathrm{M}$, et al. Treatment of beta-thalassaemiaassociated osteoporosis with zoledronic acid. $\mathrm{Br}$ | Haematol 2004; 125:91-2.

19. Gilfillan CP, Strauss BJ, Rodda CP, Bowden DK, Kean AM, Obaid M, et al. A randomized, double-blind, placebo-controlled trial of intravenous zoledronic acid in the treatment of thalassemia-associated osteopenia. Calcif Tissue Int 2006;79:138-44.

20. The International Society for Clinical Densitometry. 2007 ISCD Official Positions Brochure. Available from: http://www.iscd.org/Visitors/pdfs/ISCD2007OfficialPositionsCombined-AdultandPediatric.pdf. Accessed: April 17, 2011.

21. Genant HK, Grampp S, Glüer CC, Faulkner KG, Jergas M, Engelke K, et al. Universal standardization for dual $\mathrm{x}$-ray absorptiometry: patient and phantom cross-calibration results. J Bone Miner Res 1994;9:1503-14.

22. Fan B, Lu Y, Genant H, Fuerst T, Shepherd J. Does standardized BMD stil remove differences between Hologic and GE-Lunar state-of-the-art DXA systems? Osteoporos Int 2010;21:1227-36.

23. Voskaridou E, Christoulas D, Antoniadou L, Terpos E. Continuous increase in erythropoietic activity despite the improvement in bone mineral density by zoledronic acid in patients with thalassemia intermedia-induced osteoporosis. Acta Haematol 2008;119:40-4.

24. Rizzoli R, Burlet N, Cahall D, Delmas PD, Eriksen EF, Felsenberg D, et al. Osteonecrosis of the jaw and bisphosphonate treatment for osteoporosis. Bone 2008;42:841-7.

25. Black DM, Delmas PD, Eastell R, Reid IR, Boonen S, Cauley JA, et al. Once-yearly zoledronic acid for treatment of postmenopausal osteoporosis. N Engl J Med 2007;356:1809-22.

26. John Camm A. Review of the cardiovascular safety of zoledronic acid and other bisphosphonates for the treatment of osteoporosis. Clin Ther 2010;32:426-36.

27. Kremastinos DT, Farmakis D, Aessopos A, Hahalis G, Hamodraka E, Tsiapras D, et al. Beta-thalassemia cardiomyopathy: history, present considerations, and future perspectives. Circ Heart Fail 2010;3:451-8. 